\title{
Parameter Optimization of Double-Excess Runoff Generation Model
}

\author{
Bo Ren¹, Ji Liang ${ }^{1 *}$, Baolin Yan¹, Xiaohui Lei, Wenbo Fu', \\ Xianfeng Ni ${ }^{1}$, Jun Guo ${ }^{3,4}$ \\ ${ }^{1}$ School of Hydropower \& Information Engineering, Huazhong University of Science and Technology, \\ Wuhan, 430074, P. R. China \\ ${ }^{2}$ China Institute of Water Resources and Hydropower Research, Beijing, 010000, P. R. China \\ ${ }^{3}$ State Key Laboratory of Disaster Prevention and Reduction for Power Grid Transmission and Distribution Equipment, \\ Changsha 410129, China \\ ${ }^{4}$ State Grid Hunan Electric Company Disaster Prevention and Reduction Center, Changsha 410129, China \\ Received: 17 February 2017 \\ Accepted: 22 April 2017

\begin{abstract}
Research on the optimization of hydrological model parameters is an important issue in the field of hydrological forecasts, as these parameters not only directly impact the accuracy of forecast programs, but also relate to the development, application, and popularization of hydrological models. In this paper we selected the double-excess runoff generation model as the subject for research, and the data obtained from tens of flooding events in the Fen River Basin were used for the construction of these models. The SCE-UA and MOSCDE algorithms were then taken to optimize the models' parameters. The results showed that: as compared with the SCE-UA algorithm, higher flood forecast accuracies were obtained through model parameter optimization using the MOSCDE algorithm. During the examination period, the compliance rate of the flood peak magnitude increased from $60 \%$ to $70 \%$, while the compliance rate of the flood peak duration increased from $80 \%$ to $90 \%$. The Nash-Sutcliffe efficiency (NSE) of the flood peak magnitudes increased from 0.664 to 0.878 , which demonstrates an improvement in goodness-of-fit; the RMSE value of flood peak magnitudes also decreased from 399.8 to 236.84 , thus showing a decrease in dispersion and an improvement in goodness-of-fit. With the continuous improvements made in hydrological parameter algorithms and the creation of new optimization algorithms, there is no doubt that the optimization of hydrological model parameters will become more reasonable.
\end{abstract}

Keywords: double-excess runoff generation model, SCE-UA, MOSCD algorithm, parameter optimization

\section{Introduction}

Floods are one of the most common natural hazards throughout the world. Therefore, flood simulation

*e-mail: larkwater1@163.com modeling has received increasing attention as an important flood forecasting tool. In order to increase a model's predictive power, model reliability is always considered as a crucial topic in its development [1-5]. As early as 1970, Nash and Sutcliffe stated that if it was hoped to use the model for watersheds without records, it was essential to obtain some guide to the realism of model parts and 
the accuracy of parameter values [6-10]. Hydrological models refer to all physical, mathematical, and logical structures that are constructed for studying the patterns of hydrological changes in hydrological phenomena and its processes; all physical and mathematical models related to hydrology are collectively known as hydrological models [11]. Early hydrological models were mostly black-box models with only inputs and outputs, and that do not consider the physical processes that occur within the catchment. If a change in the hydrological conditions of a catchment occurs, the parameters of a black-box model can be rendered unsuitable for use. Progress that has been made in hydrology and the expansion of the knowledge of hydrological phenomena, and its associated processes within catchments have led to the development of lumped conceptual hydrological models; the bestknown lumped conceptual hydrological models in the world are currently: the Stanford model, the Sacramento model, and the SCS model [12]. Research on lumped conceptual models in China began somewhat later than in the rest of the world. Nevertheless, through insights gathered from hydrological models around the world, a number of models with regional features that are suitable for use in local regions have been developed, with the most widely applied models being the Xinanjiang model, the double-excess model, and the Northern Shaanxi model [13]. The advances of global "informationization" and developments in space technologies have also led to the gradual development of distributed hydrological models, which include the TOPMODEL, SHE, and MIKESHE models [14].

In the development and application of hydrological models, besides difficulties in its construction and composition, another difficulty lies in accurately determining model parameters. The accuracy of model parameters directly affects the accuracy of hydrological model forecast programs, as the appropriate model parameters are necessary for hydrological model forecasts to come closer to reality. As hydrological models usually have a large number of parameters and are affected by multiple factors - such as hydrometeorological factors, the underlying surface, and human factors hydrological models are characteristically uncertain, highly dimensional, highly nonlinear, and generate data that can be difficult to interpret. These issues make it difficult to ascertain the parameters of hydrological models [15]. Most traditional optimization algorithms are local optimization algorithms that are not capable of obtaining globally optimized parameters. These algorithms lack effectiveness and stability, and are difficult to have a good effect in practical applications. With the progress that has been made in scientific technologies and the ubiquity of computers, algorithms that are widely applicable and capable of performing global optimizations are now beginning to appear, and become increasingly mature.

Currently, the conceptual runoff generation model is maturely developed and widely used. Flood forecasting using this type of model can meet the accuracy requirements in humid areas in China. In this study, the

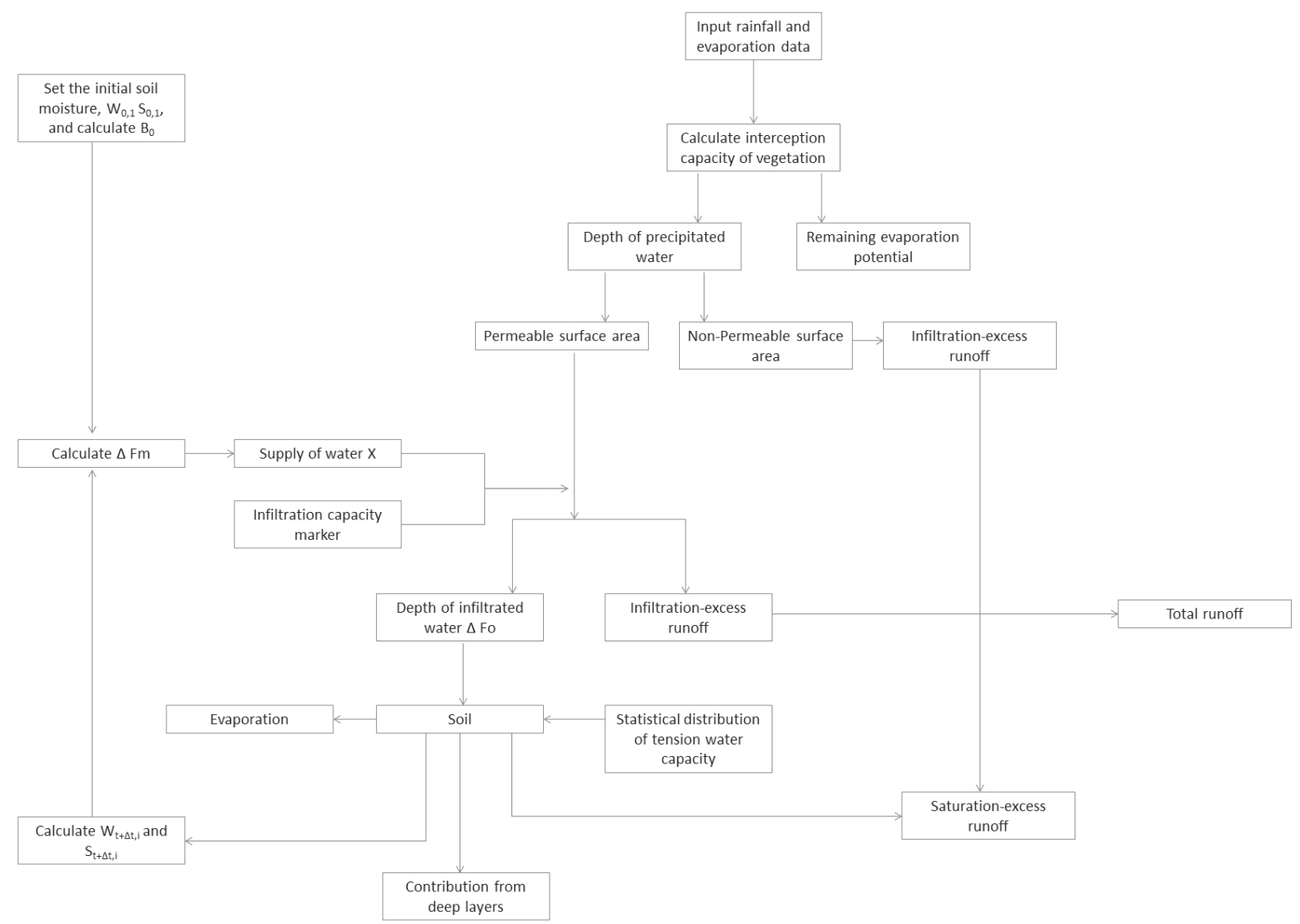

Fig. 1. Schematic diagram of the double-excess runoff generation model. 
double-excess runoff generation model was selected as the test subject for parameter optimizations using the SCE-UA and MOSCDE algorithms. Through model optimizations using the data that was obtained from the tens of flood events that have occurred in the Fen River Basin, it was found that the MOSCDE optimization algorithm resulted in more accurate flood forecasts than the SCE-UA optimization algorithm.

\section{Methodology}

\section{The Double-Excess Runoff Generation Model}

\section{A Brief Description of the Model}

The double-excess runoff generation model was proposed by Wang et al. [16] following their analyses of runoff generation characteristics in semi-arid and semi-humid regions. The runoff generation theory of this model refers to a third runoff generation mode besides infiltration-excess and saturation-excess runoff generation: in semi-arid and semi-humid regions, the total runoff produced by rainfall is mainly composed of surface runoff, interflows, and groundwater runoff, but with different proportions for each part. In catchments that have experienced a long bout of drought, rainfalls with high intensity and short durations will generate surface runoff; since there is a lack of infiltration into the ground and soil interflows in this situation, surface runoff then becomes the sole component of total runoff. By contrast, the soil layer above the weakly permeable layer become overly saturated in catchments that have experienced long or repeated rainfalls, causing the occurrence of soil interflows. The volume of the soil interflow depends on the volume of water that is in excess of the holding capacity and the area of the catchment that is experiencing this excess. When soil interflows do not contribute to total runoff, the double-excess runoff mode becomes equivalent to the infiltration-excess runoff mode, whereas if surface runoff does not dominate total runoff, the double-excess runoff mode becomes equivalent to the saturation-excess runoff mode. In other words, the saturation-excess and infiltration-excess runoff modes represent two special cases of the double-excess runoff generation model [17].

The composition of the double-excess runoff generation model was designed according to the physical mechanisms of the three types of water flow, as well as the runoff generation modes and characteristics of semi-arid/semi-humid regions. This includes these five primary components: the fabricated historical patterns of infiltration capacity subunits, the distribution of filtration capacity in the river basin, surface runoff, soil interflows, soil evaporation, and pre-rain soil moisture [18]. A schematic diagram of the double-excess model is shown in Fig. 1.

\section{Model Parameters}

A hydrological model is comprised of two components: the model's structure and its parameters. The structure reflects on the basic relationships between rainfall and runoff and conversion rulesets, while the model parameters are an overall reflection of the effects of the catchment's natural geographical characteristics on the relationship between rainfall and runoff. These parameters generally do not change with the model that is being applied, but differ according to the geographical region that is being analyzed [19]. The basic parameters of the double-excess model and their corresponding value ranges are shown in Table 1.

\section{Algorithms for Optimizing Model Parameters}

\section{The SCE-UA Algorithm}

The SCE-UA algorithm is a comprehensive optimization algorithm that was developed by Duan et al. [20] in 1992 on the basis of the simplex algorithm created by Nelder and Mead in 1965 [21], combined with the basic concepts of biological evolutionary principles and genetic algorithms that imitate nature.

Table 1. Basic parameters of the double-excess model.

\begin{tabular}{|c|c|c|c|}
\hline $\begin{array}{c}\text { Parameter } \\
\text { Name }\end{array}$ & Description of the parameter & $\begin{array}{c}\text { Units of the } \\
\text { parameter }\end{array}$ & Value range \\
\hline SR & Macroscopic absorption rate of fully-desiccated soil & $(\mathrm{L} / \mathrm{T})$ & $35-60$ \\
\hline $\mathrm{KS}$ & Macroscopic hydraulic conductivity of saturated soil & $(\mathrm{L} / \mathrm{T})$ & $1-15$ \\
\hline $\mathrm{c}$ & Pore-size grades of the soil & Dimensionless & $0 \sim 4$ \\
\hline $\mathrm{b}$ & Linearity of the watershed's normalization curve & Dimensionless & $\begin{array}{c}\text { Obtained from forested regions } \\
\mathrm{b}>1\end{array}$ \\
\hline$\alpha 0$ & Critical rainfall intensity of the runoff & Dimensionless & $0 \sim 1$ \\
\hline$\delta \mathrm{i}$ & Side-row coefficients & Dimensionless & \\
\hline $\mathrm{JL}$ & Interception capacity of vegetation within the \\
catchment & & \\
\hline
\end{tabular}


The basic principle of the SCE-UA algorithm is the random selection of population sample points within a feasible space, followed by the partitioning of the population into several units. Every unit contains a suitable number of points, and every unit is evolved based on a statistical "reproduction" process. After several generations of evolution, the entire population is reshuffled, and the points are reassigned to each population unit to ensure information sharing and to avoid falling into local optima. The entire population will converge toward the neighborhood of the global optimum after several generations of evolution, provided that there is a sufficiently large initial population size [22]. Since the SCE-UA algorithm uses single-objective optimization, the only consideration in judging the superiority or inferiority of each population unit is the corresponding objective function value of each individual population. Therefore, the average error is usually chosen as the objective function for the optimization of hydrological forecast model parameters. The procedure for calibrating parameters using the SCE-UA algorithm is as follows:

1. The rainfall runoff data of some sites in the catchment were sorted, and the appropriate flood events were selected; these were divided into calibration and examination periods that were then used for the calibration and examination of model parameters.

2. The flood event data was input into the parameter optimization model, and the parameter values were initialized within the model.

3. The double-excess model was utilized with every parameter value to calculate production and runoff.

4. The average error of each group of parameter values was calculated and adopted as the objective function for the optimization of model parameters.

5. The SCE-UA calculation was performed to obtain the optimal set of parameters through automatic optimization.

6. A final test was performed on each group of parameters using flood events in the examination period in order to obtain the final model parameters.

\section{The MOSCDE Algorithm}

The MOSCDE algorithm was developed by Guo et al. [23] in 2013 through their efforts to optimize and improve the SCE-UA algorithm. MOSCDE improves on some of the SCE-UA algorithm's weaknesses, such as the SCEUA's relative lack of speed and its reliance on singular objective functions.

The MOSCDE algorithm optimizes the SCE-UA algorithm through the Pareto dominance framework, and utilizes relevant experiences of the population units in the evolutionary process to improve the self-regulating capacity and reliability of the algorithm. The MOSCDE algorithm also fully utilizes computational data by using global optimization algorithms and DE algorithms as its core algorithms, thus improving its convergence speed and computational efficiency.
Unlike the SCE-UA algorithm, the MOSCDE algorithm is a multi-objective optimization algorithm. The compliance rate of flood peaks (QR), the compliance rate of flood peak durations (QT), and the deterministic coefficient of flood events (DC) were selected as the objective functions for objective function value calculations. The procedure for optimizing model parameters using MOSCDE is as follows:

1. The rainfall runoff data of some site in the catchment was sorted, and the appropriate flood events were selected; these were divided into calibration and examination periods, which were then used for the calibration and examination of model parameters.

2. The flood event data were input into the parameter optimization model, and the parameter values were initiated within the model.

3. The double-excess model was utilized with every parameter value to calculate production and runoff.

4. The flood peak compliance rate (QR), peak duration compliance rate (QT), and deterministic coefficient (DC) were calculated for each group of parameter values, which were then adopted as the objective functions for model parameter optimization.

5. The MOSCDE calculation was performed to obtain the optimal set of parameters through automatic optimization.

6. A final examination was performed on every group of parameters using flood events in the examination period in order to obtain the final model parameters.

\section{Results and Discussion}

The Fen River Basin was selected as the test subject for double-excess modelling in this study. The rainfall and runoff data of the Upper Fen River Basin from 1958 to 1989 were collected and sorted, and the 34 flood events that occurred within this time period were used for the construction of a double-excess model, in which the 24 flood events from 1958 to 1982 were utilized for calibrating the model while the 10 flood events from 1982 to 1989 were employed for examining the model. The SCE-UA and MOSCDE algorithms were applied to optimize and calibrate the model using the 24 selected flood events. A comparative analysis was then performed on these results to select the best-performing parameter calibration algorithm.

\section{Data Analysis}

The Fen River Basin lies in the center of Shanxi Province, with a width of $188 \mathrm{~km}$ in an east-west direction, and a length of $412 \mathrm{~km}$ north-south. It is a relatively long and narrow river basin that moves north-south, with a total surface area of $39,471 \mathrm{~km}^{2}$ [24]. As the basin is located within the inland region of the country, it has a monsoon-type mainland climate with highly seasonal precipitation with most of the 
Table 2. SCE-UA optimized parameter values.

\begin{tabular}{|c|c|c|c|c|c|c|c|}
\hline Parameter & Range & Parameter & Range & Parameter & Range & Parameter & Range \\
\hline$\omega$ & 0.652 & Zlm & 20.0 & $\mathrm{a} 0$ & 0.019 & Ks & 5.878 \\
\hline $\mathrm{Sr}$ & 22.925 & $\mathrm{C}$ & 10.0 & $\mathrm{~B} 1$ & 1.538 & $\beta 0$ & 1.277 \\
\hline $\mathrm{Wm}$ & 20.0 & $\mathrm{Sm}$ & 55.718 & $\mathrm{Cc}$ & 4.986 & $\sigma \mathrm{e}$ & 0.017 \\
\hline$\lambda \mathrm{a}$ & 0.089 & $\mathrm{n}$ & 1.0 & $\mathrm{~K}$ & 2.729 & & \\
\hline
\end{tabular}

annual precipitation of the basin falling June to September. Due to the relatively large surface area of the basin, its hydrometeorological conditions are complex. Most floods that occur within the basin are caused by repeated storms that usually occur in July and August [25], and there is a relative abundance of information on flood events that have occurred within the basin. This study chose to use the historical hydrometeorological data of the Fen River basin for rainfall and evaporation analysis.

\section{Rainfall Analysis and Calculations}

In this study, the data from the following rainfall measurement stations within the Fen River basin were selected for analyses: Songjiaya, Ximafeng, Gezidong, Kangjiahui, Xinbao, Dujia village, Huaidao, Dongmafang, and Tang-er. Data collected at the Jingwen hydrological station were also included. Average rainfall was then calculated using the Thiessen polygon method.

\section{Evaporation Analysis}

As there was no direct evaporation data within the research area, the daily evaporation data from nearby Fen River reservoir hydrological stations were taken as a reference for calculating the average evaporation per hour. This was used as the evaporation input of the model.

\section{Model Parameters and Algorithm Settings}

\section{SCE-UA Parameters and Algorithm Settings}

The single objective SCE-UA algorithm was applied to determine the parameters of the Fen River basin's double-excess model, and its objective function was the mean square error that is commonly used for hydrological forecasts.
There were originally 18 parameters within the doubleexcess model [26], but during the initialization process, the following initial parameters of the time period were set to zero: remaining water depth zl_1, saturation level $\mathrm{B} 0$, tension water $\mathrm{W} 1$, and free water $\mathrm{S} 1$; because the values of these parameters simply change continuously over time, only 13 parameters needed to be optimized. With the addition of the two parameters required by the Nash unit hydrograph, there were then a total of 15 parameters that need to be determined, in practice. The initial model parameters of the SCE-UA algorithm are as follows: number of samples, $\mathrm{m}=2 \mathrm{n}+1$; the number of samples selected for each subunit is: $\mathrm{q}=\mathrm{n}+1, \mathrm{q}=7$; 500 iterations. The results of the parameter optimization performed by the SCE-UA parameter optimization model are shown in Table 2.

\section{MOSCDE Parameters and Algorithm Settings}

The multi-objective MOSCDE optimization algorithm was applied to perform a multi-objective optimization and calibration of the double-excess model of the Fen River basin. The objective functions for this optimization were flood peak compliance rate, peak duration compliance rate, and the determining coefficient.

The initialization parameters selected for the MOSCDE algorithm are as follows: $n$ OfPop $=100$, $n O f C o m=2$, stepsBeforeShuffle $=7$, archiveSize $=100$, $\mathrm{DE}$ evolutionary parameters $\mathrm{CR}=0.2$, and maxIter $=500$ [27]. After the MOSCDE model parameters were set, the parameter optimization calculations on runoff generation models may then be performed. The model parameter optimization results are shown in Table 3.

\section{Selecting Performance Metrics}

Compliance rate $\left(Q_{r}\right)$, Nash-Sutcliffe efficiency (NSE), and root-mean-square error (RMSE) performance

Table 3. MOSCDE optimized parameter values.

\begin{tabular}{|c|c|c|c|c|c|c|c|}
\hline Parameter & Range & Parameter & Range & Parameter & Range & Parameter & Range \\
\hline$\omega$ & 0.106 & Zlm & 19.98 & $\mathrm{a} 0$ & 0.005 & Ks & 10.0 \\
\hline $\mathrm{Sr}$ & 15.452 & $\mathrm{C}$ & 10.0 & $\mathrm{~B} 1$ & 1.684 & $\beta 0$ & 8.139 \\
\hline $\mathrm{Wm}$ & 19.987 & $\mathrm{Sm}$ & 65.067 & $\mathrm{Cc}$ & 1.024 & $\sigma \mathrm{e}$ & 0.017 \\
\hline$\lambda \mathrm{a}$ & 0.454 & $\mathrm{n}$ & 1.787 & $\mathrm{~K}$ & 1.0 & & \\
\hline
\end{tabular}


Table 4. Statistical results of flood events as forecasted by the two different optimization algorithms.

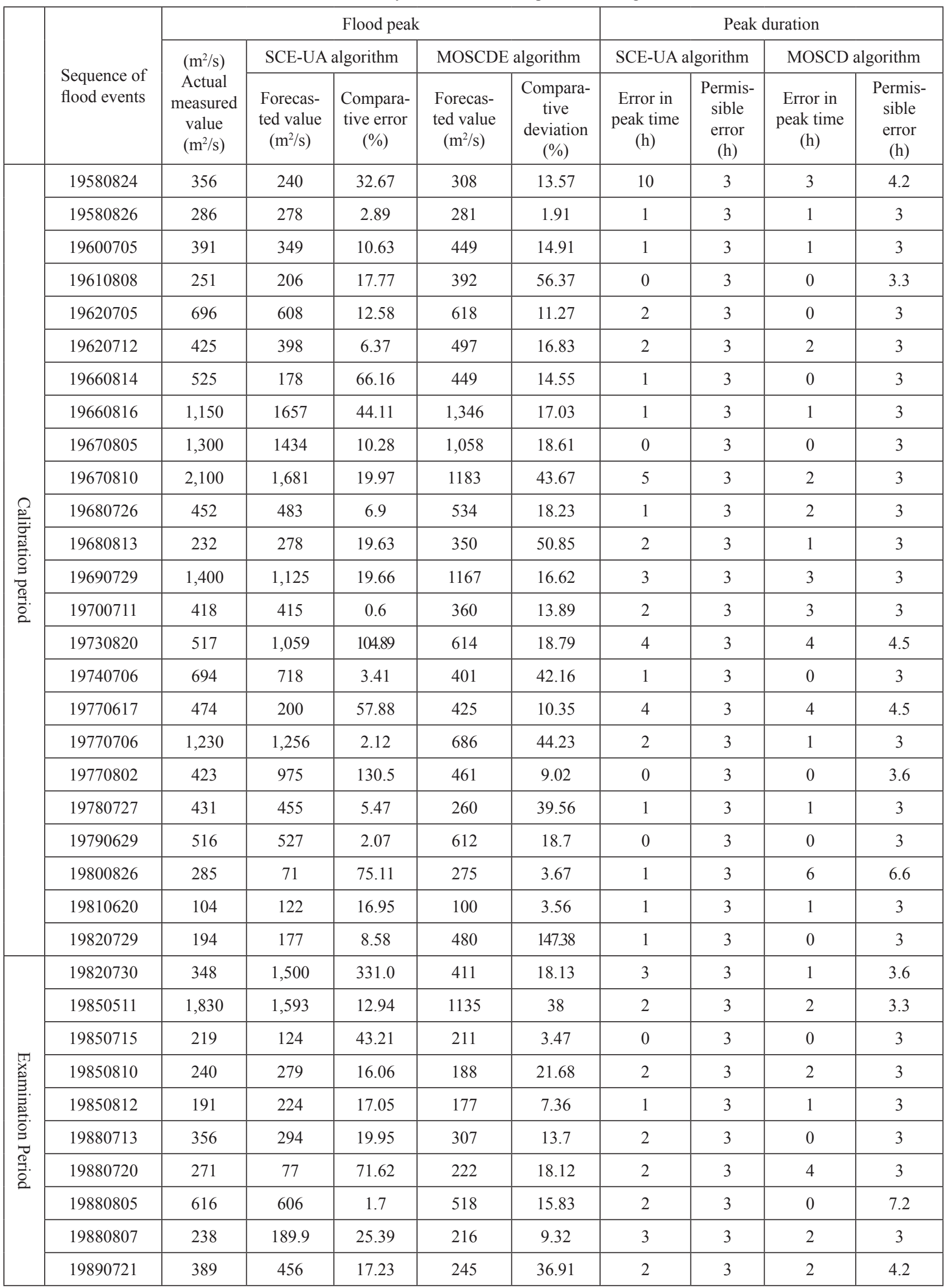



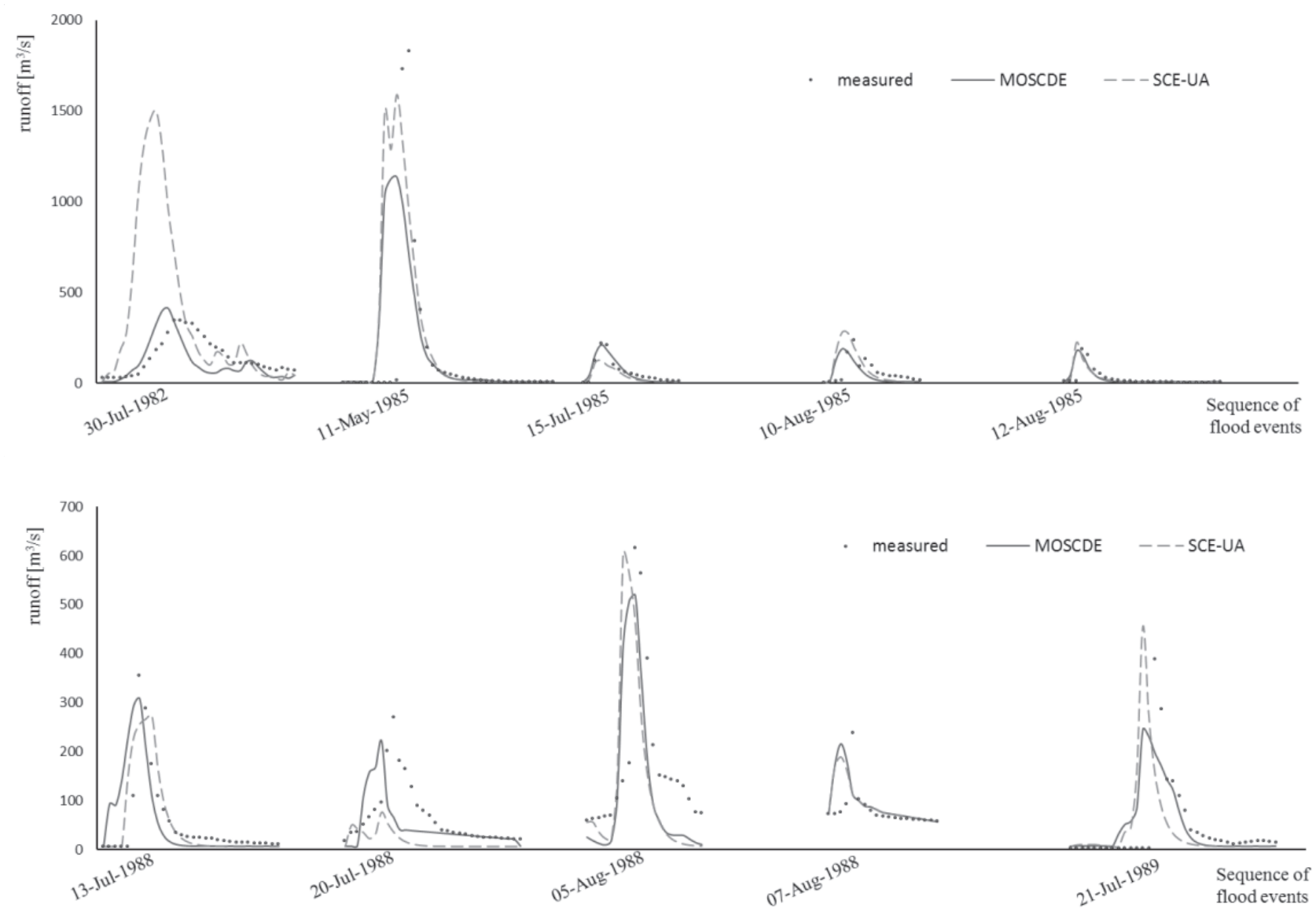

Fig. 2. Comparison of model simulation and observation for 10 floods.

metrics were used to evaluate the forecasting capabilities of the SCE-UA and MOSCDE algorithms.

The definition of Nash-Sutcliffe efficiency (NSE) is shown in Equation (1), where $Q_{i}$ refers to the actual measured value and $Q_{c}$ refers to the value forecasted by the model. The fit between forecasted values and actually measured values increases as the numerical value of the NSE approaches 1 [28].

The root-mean-square error (RMSE) is defined in Equation (2), where $Q_{i}$ represents the actual measured value while $Q_{c}$ represents the value forecasted by the model. As the RMSE value decreases, the dispersion decreases, which implies an improvement in the fit between actually measured and forecasted values [29].
Results Analysis

The 24 flood events that occurred within the calibration period were simulated and evaluated using the SCE-UA and MOSCDE algorithms, then taken as a reference for the construction of flood forecasting programs. The 10 flood events in 1982-1989 were then employed to examine the predictive accuracy of the flood forecasting programs; the results of this examination are shown in Table 4.

The 10 flood events that occurred within the inspection period were simulated and evaluated using the doubleexcess runoff generation model by the SCE-UA and MOSCDE algorithms, then drew the flood hydrograph of

Table 5. A comparison of the forecast accuracies of the double-excess models optimized using the MOSCDE and SCE-UA algorithms.

\begin{tabular}{|c|c|c|c|c|c|c|c|c|}
\hline \multirow{2}{*}{$\begin{array}{c}\text { Performance } \\
\text { metric }\end{array}$} & \multicolumn{4}{|c|}{ Flood peak runoff } & \multicolumn{4}{c|}{ Flood peak appearance } \\
\cline { 2 - 9 } & $\begin{array}{c}\text { Calibration } \\
\text { period }\end{array}$ & $\begin{array}{c}\text { Examination } \\
\text { period }\end{array}$ & $\begin{array}{c}\text { Calibration } \\
\text { period }\end{array}$ & $\begin{array}{c}\text { Examination } \\
\text { period }\end{array}$ & $\begin{array}{c}\text { Calibration } \\
\text { period } \\
\text { algorithm }\end{array}$ & $\begin{array}{c}\text { Examination } \\
\text { period }\end{array}$ & $\begin{array}{c}\text { Calibration } \\
\text { period }\end{array}$ & $\begin{array}{c}\text { Examination } \\
\text { period }\end{array}$ \\
\hline$Q r$ & $70.8 \%$ & $60 \%$ & $75 \%$ & $70 \%$ & $90 \%$ & $80 \%$ & $100 \%$ & $90 \%$ \\
\hline NSE & 0.733 & 0.664 & 0.664 & 0.878 & - & - & - & - \\
\hline RMSE & 241.3 & 399.8 & 256.1 & 236.84 & - & - & - & - \\
\hline
\end{tabular}


each flood event based on forecast results (Fig. 2). From this figure, we can see that the results of the MOSCDE algorithm are closer to the measured series.

The performance metrics $Q_{r}$, NSE, and RMSE were used to compare the forecast accuracies of double-excess models that were optimized using the SCE-UA and MOSCDE algorithms in the calibration period. These results are shown in Table 5 .

Based on Table 5, it is shown that the multi-objective MOSCDE algorithm has improved the accuracy of the double-excess model in forecasting flood events, as shown by the $Q_{r}$ parameter. The compliance rate of the flood peak magnitude increased from $60 \%$ to $70 \%$, while the flood peak duration compliance rate increased from $80 \%$ to $90 \%$. Furthermore, during the calibration period, the compliance rate of the flood peak magnitude increased from $70.8 \%$ to $75 \%$, while the compliance rate of the flood peak duration increased from $91.7 \%$ to $100 \%$.

During the examination period, it is shown that the NSE of the MOSCDE algorithm is closer to 1, as compared with the SCE-UA algorithm, indicating a higher goodness-of-fit. As for the RMSE index, the MOSCDE algorithm also resulted in a lower RMSE value, and thus a lower dispersion and higher goodness-of-fit.

From the above analyses, it is shown that the MOSCDE algorithm is a more optimal method for optimizing the parameters of double-excess runoff generation models, and that the forecast results produced from MOSCDEoptimized models are also more reliable.

\section{Conclusions}

Optimizing and calibrating hydrological parameters has always been difficult in the field of hydrological forecasts, as these parameters directly affect the accuracy of forecasting programs and the future development and popularization of hydrological models. The results of this study showed that as we deepen our understanding of computers, and cross-disciplinary developments become more common in various fields of study, more and more algorithms that are based on physical theories and global optimization will be put forward, such as the RBF neural network algorithm, the ant colony optimization algorithm, and the particle swarm optimization algorithm. Existing optimization algorithms are also being improved at a rapid rate; for instance, the MOSCDE algorithm that is the focus of this study is an improved version of the SCE-UA algorithm. It is believed that with the continuous improvement of these algorithms, optimizing hydrological model parameters will become increasingly accurate, which will in turn improve the accuracy of hydrological forecasting programs.

\section{Acknowledgements}

This research was financially supported by urgency operation control and demonstration in Middle Line of
Water Diversion of South to North (2015BAB07B03). Language editing and improvement by Cactus Communications is also greatly appreciated.

\section{References}

1. HRACHOWITZ M., SAVENIJE H.H.G., BLOSCHL G. et al., A decade of Predictions in Ungauged Basins (PUB) - a review, Hydrological Sciences Journal, 6 (58), 1198, 2013.

2. EUSER T., WINSEMIUS H.C., HRACHOWITZ M., FENICIA F., UHLENBROOK S., SAVENIJE H.H.G. A framework to assess the realism of model structures using hydrological signatures, Hydrology andEarthSystemSciences, 5 (17), 1893, 2013.

3. GHARARI S., HRACHOWITZ M., FENICIA F., GAO H., SAVENIJE H.H.G. Using expert knowledge to increase realism in environmental systemmodels can dramatically reduce the need for calibration, Hydrology andEarth SystemSciences, 12 (18), 4839, 2014.

4. GAO H., HRACHOWITZ M., FENICIA F., GHARARI S., SAVENIJE H.H.G. Testing the realism of a topographydriven model (FLEX-Topo) in the nested catchments of the Upper Heihe, China, Hydrology and Earth System Sciences, 5 (18), 1895, 2015.

5. NASH J.E., SUTCLIFFE J.V. River flow forecasting through conceptual models part I-a discussion of principles, Journal of Hydrology, 3 (10), 282, 1970.

6. YIPING GUO, SHUGUANG LIU, BAETZ B.W. Probabilistic rainfall-runoff transformation considering both infiltration and saturation excess runoff generation processes. Water Resources Research, 48, W06513, doi:10.1029/2011WR011613, 2012.

7. PENGNIAN HUANG, ZHIJIA LI, CHENG YAO, QIAOLING LI, MEICHUN YAN Spatial Combination Modeling Framework of Saturation-Excess and InfiltrationExcess Runoff for Semihumid Watersheds. Advances in Meteorology. 2016, doi.org/10.1155/2016/5173984

8. BRUNO MAJONEA, ALBERTO BELLINA, ANDREA BORSATOB Runoff generation in karst catchments: multifractal analysis. Journal of Hydrology, 294, 176, 2004

9. BRUNO MAJONE, ANDREA BERTAGNOLI, ALBERTO BELLIN A non-linear runoff generation model in small Alpine catchments. Journal of Hydrology, 385, 300, 2010.

10. STROUHAL, LUDEK, DAVID, VÁCLAV Role of Infiltration and Saturation Excess in Rainfall-Runoff Modelling in Small Catchements. Journal of Civil Engineering, 8 (1), 5, 2016.

11. CHUN FU, QIANG ZHANG Summary of hydrological catchment models. Jiangxi Science, 04, 588, 2008.

12. CHENGMEI LUAN Study on the optimization of hydrological catchment model parameters. Hohai University, 2005.

13. XIAOHUA YANG, ZHIFENG YANG, JIANQIANG LI, ZHENYAO SHEN, QIANG CHEN Prospects and research on hydrological model parameter identification algorithms. Progress in Natural Science, 06, 657, 2006.

14. XIANGYANG LI Studies on the Optimization and uncertainty analysis of hydrological model parameters. Dalian University of Technology, 2006.

15. DELONG LI, XIANYUN CHENG, HAO YANG, PING HUANG Study on artificial intelligence optimization algorithms for auto-calibration of hydrological models [J].

16. LI LI Development and application of flood forecasting models in semi-arid and semi-humid catchments. Xi'An 
University of Technology, 2009.

17. LI LI, YAOXING YAN, BING CHEN Application of the Double-Excess Model to Semi-Humid Areas. Journal of North University of China (Natural Science Edition), 01, 62,2008

18. HUA JIN The theories and applications study of doubleexcess runoff generation model. China University of Geosciences (Beijing), 2006.

19. JINTAO LIU, HUIQING SONG, XINGNAN ZHANG, XI CHEN A discussion on advances in theories of Xinanjiang Model. Journal of China Hydrology, 01, 1, 2014.

20. CHAO GU Research and implementation of mountain flood warning in improved SCEM-UA algorithm and Xin'anjiang model. Nanjing University of Information Science and Technology, 2014.

21. ZHANGJUN LIU, SHENGLIAN GUO, TIANYUAN LI, XINGJUN HONG Comparative study of Bayesian probabilistic flood forecasting models [J]. Journal of Hydraulic Engineering, 09, 1019, 2014.

22. HUIJUN XU, YANGBO CHEN, BIQIU ZENG, JINXIANG HE, ZHENGHONG LIAO Application of SCE-UA algorithm to parameter optimization of Liuxihe model. Tropical Geography, 01, 32, 2012.

23. JUN GUO, JIANZHONG ZHOU, CHAO ZHAOU, GUANGQIAN WANG, YONGCHUAN ZHANG Multiobjective optimization for conceptual hydrological models. Advances in Water Science, 04, 447, 2012.
24. SHUJIE LIANG Analysis on Characteristics of Fenhe River Floods. Yellow River, 05, 17, 2005.

25. JIALAN SUN, XIAOHUI LEI, JUNXI YIN, YUNZHONG JIANG, YUANSHENG LI Application of distributed flood forecasting model to Fenhe River Basin [J]. Water Resources and Hydropower Engineering, 01, 21, 2014.

26. HAO GE Parameters of Double Infiltration Model Calibration Based on SCE-UA. Water Conservancy Science and Technology and Economy, 07, 26, 2016.

27. JUN GUO, JIANZHONG ZHOU, QIANG ZOU, LIXIANG SONG, YUNGUAN ZHANG Study on Multi-objective parameter optimization of Xinanjiang model. Journal of China Hydrology, 01, 1, 2013.

28. JUN GUO, JIANZHONG ZHOU, HAO WANG, QIANG ZOU Structure optimization and parameter calibration of empirical hydrological model under the multi-objective framework. Journal of Hydroelectric Engineering, 02, 1, 2014.

29. FEIFEI SUN, QIN XU, LILIANG REN, CHANGQING LIN, RUI TONG An analysis of the parameter sensitivity of hydrological models. China Rural Water and Hydropower, 03, 92, 2014.

30. GUODONG LIU, ZHENXUE DAI, BING XING, YAN WANG, YUCHUAN MENG, JUN LI Application of bioinspired algorithms for inverse problems of groundwater models: status and prospects. Hydrogeology and Engineering Geology, 01, 41, 2016. 